\title{
Various Treatment Options for the Single Implant in the Mandibular Anterior Region
}

\begin{abstract}
The challenges associated with replacing missing tooth at anterio mandible include limited mesial to distal alveolar ridge length, challenging surrounding anatomy, and potentially high esthetic requirements. Several treatment options currently exist for patients to replace a mandibular incisor. Three main categories exist: Removable Prosthesis, Fixed Partial Prosthesis, and Implant Retained Prosthesis.

Small diameter implants are often chosen for cases where there is a reduced availability of alveolar ridge width or interdental space, as opposed to other treatment options including Fixed Dental Prosthesis (FDP) and Removable Dental Prosthesis (RDP) dictate performing teeth preparation to neighboring sound teeth structures and leads to increased residual ridge resorption rate in removable prosthesis. Small diameter implant, together with the use of platform switching, can reduce bone resorption when the implants are placed closer than $1.5 \mathrm{~mm}$ to the adjacent teeth. The purpose of this case report is to review and report the result of the techniques that can be used in patients who have limited mesial-distal distance between implant and adjacent teeth.
\end{abstract}

\section{Introduction}

The replacement of a mandibular incisor is a reasonably common dental need warranting special consideration. Some of the challenges associated with the anterior mandible are limited space, challenging surrounding anatomy, and potentially high esthetic requirements. The purpose of a treatment plan is formulating a logical sequence of treatment designed to restore the patient's dentition to good health, with optimal function and appearance [1]. Bain stated, an ideal treatment plan is to achieve the best possible long-term outcomes for the patient, while addressing all patient concerns and active disease, with the minimum necessary intervention [2]. Several treatment options currently exist for patients replacing a mandibular incisor. Three main categories exist: Removable prosthesis, Fixed partial prosthesis, and Implant retained prosthesis (Figure 1).

Dental implant restorations have been documented to have a high degree of success for completely and partially edentulous patients. This is also true in studies of single implant supported restorations [3-7]. A requirement for successful implant placement is the presence of adequate bone volume to insure minimum of $2 \mathrm{~mm}$ of bone thickness facial to the implant especially in esthetic zone, a minimum of $1 \mathrm{~mm}$ lingual and sufficient interdental space to allow a standard-diameter implant to be inserted. Procedures to increase facial-lingual bone volume, including guided bone regeneration $[8,9]$ and block grafting [10], have been used to increase available bone. Degidi et al. showed a $99.4 \%$ success rate for 510 narrow diameter implants $(<3.75 \mathrm{~mm})$ over 8 years, with some evidence of increased success for implants wider than $3.4 \mathrm{~mm}$ [11]. A clinical study of 182 $3.3 \mathrm{~mm}$-diameter implants in severely resorbed maxillae, without any bone augmentation performed, revealed a survival rate of $99.4 \%$

\section{Journal of Oral Biology}

\section{Abdullah Alodadi, Tekunatorn Kreingsak, Manasse Maryse, Leon Angie, Hazlina B. Abdul Ghani and Cho Sang-Choon}

Ashman Department of Implant Dentistry and Periodontology, College of Dentistry, New York University, USA

\section{*Address for Correspondence}

Abdullah Alodadi, Ashman Department of Implant Dentistry and Periodontology, College of Dentistry, New York University, USA; E-mail: asa541@nyu.edu

Submission: 24 February, 2015

Accepted: 04 April, 2016

Published: 11 April, 2016

Copyright: (๑) 2016 Alodadi A. This is an open access article distributed under the Creative Commons Attribution License, which permits unrestricted use, distribution, and reproduction in any medium, provided the original work is properly cited.

Reviewed \& Approved by: Dr. Walid Fakhouri, Department of Diagnostic and Biomedical Sciences, School of Dentistry, University of Texas Health Science Center in Houston, TX, USA

[12]. Z insli et al. reported a $98.7 \% 5$-year survival rate for 298 of the same reduced diameter implants, over a 10 -year period. Implants placed in regenerated bone show high degrees of success [13-15]. However, grafting cannot solve a mesial-distal space problem. Many authors have suggested that a minimum distance of $1.5 \mathrm{~mm}$ must be maintained between the tooth and implant to preserve the bone and interdental papilla in the area, thereby improving the success rate of the implant and the esthetic outcome. To adhere to this requirement, implant manufacturers have introduced smaller-diameter implants ( 3.0 to $3.5 \mathrm{~mm}$ ). Nevertheless, these implants still require a minimum mesio-distal space of 6.0 to $6.5 \mathrm{~mm}$ to allow adequate implant-totooth distance. In some cases, maintaining this space is difficult, if not impossible. For example, in a patient with loss of one lower incisor, oftentimes the edentulous spaces are less than $6 \mathrm{~mm}$. Therefore, it's impossible to place an implant, which has a diameter of more than $3 \mathrm{~mm}$ and maintain a $1.5 \mathrm{~mm}$ distance on each side from natural adjacent teeth.

To solve this mesial-distal space problem, 3 options have been suggested. 1) Extract a neighboring lower incisor and make a cantilever crown (2 unit fixed restoration) (Figure 2). With this option, a $3.75-4.75 \mathrm{~mm}$ diameter implant can be placed which has adequate implant-to-bone surface area and reduce the risk of implant

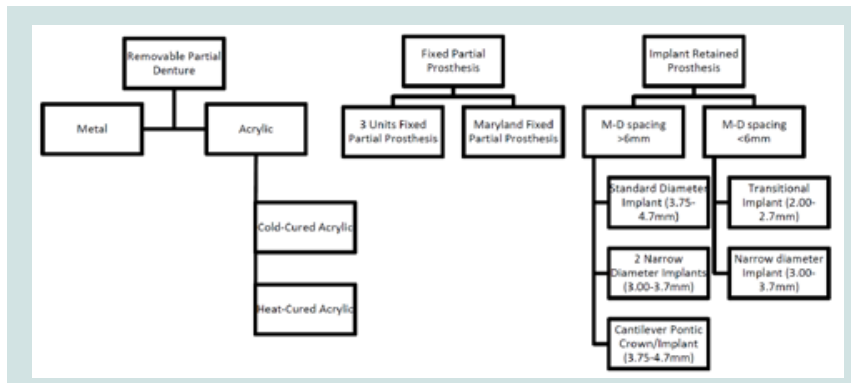

Figure 1: Treatment options for the mandibular anterior region. 
Citation: Alodadi A, Kreingsak T, Hazlina B, Ghani A, Angie MML, et al. Various Treatment Options for the Single Implant in the Mandibular Anterior Region. J Oral Bio. 2016; 3(1): 7.

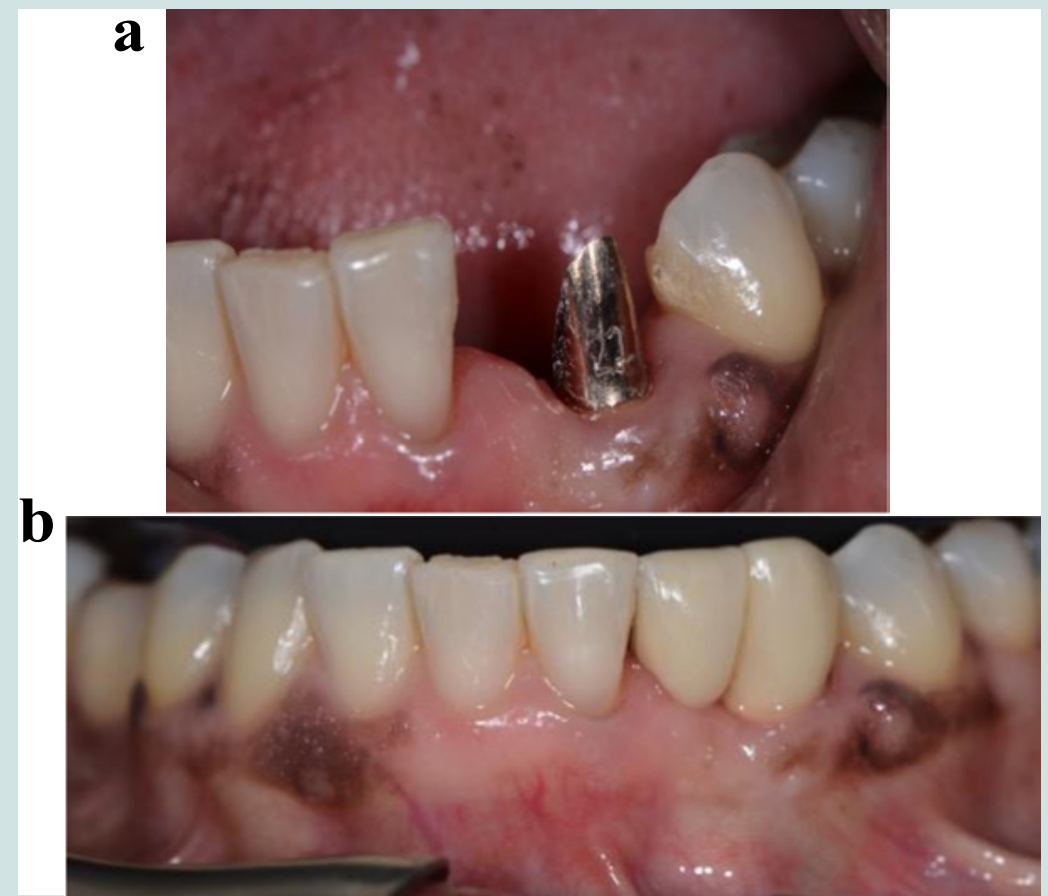

Figure 2: Case illustration of cantilever crown over one standard implant. (a) Final abutment on implant placed in canine area. (b) Final clinical presentation after cementation of two units restoration with mesial cantilever.

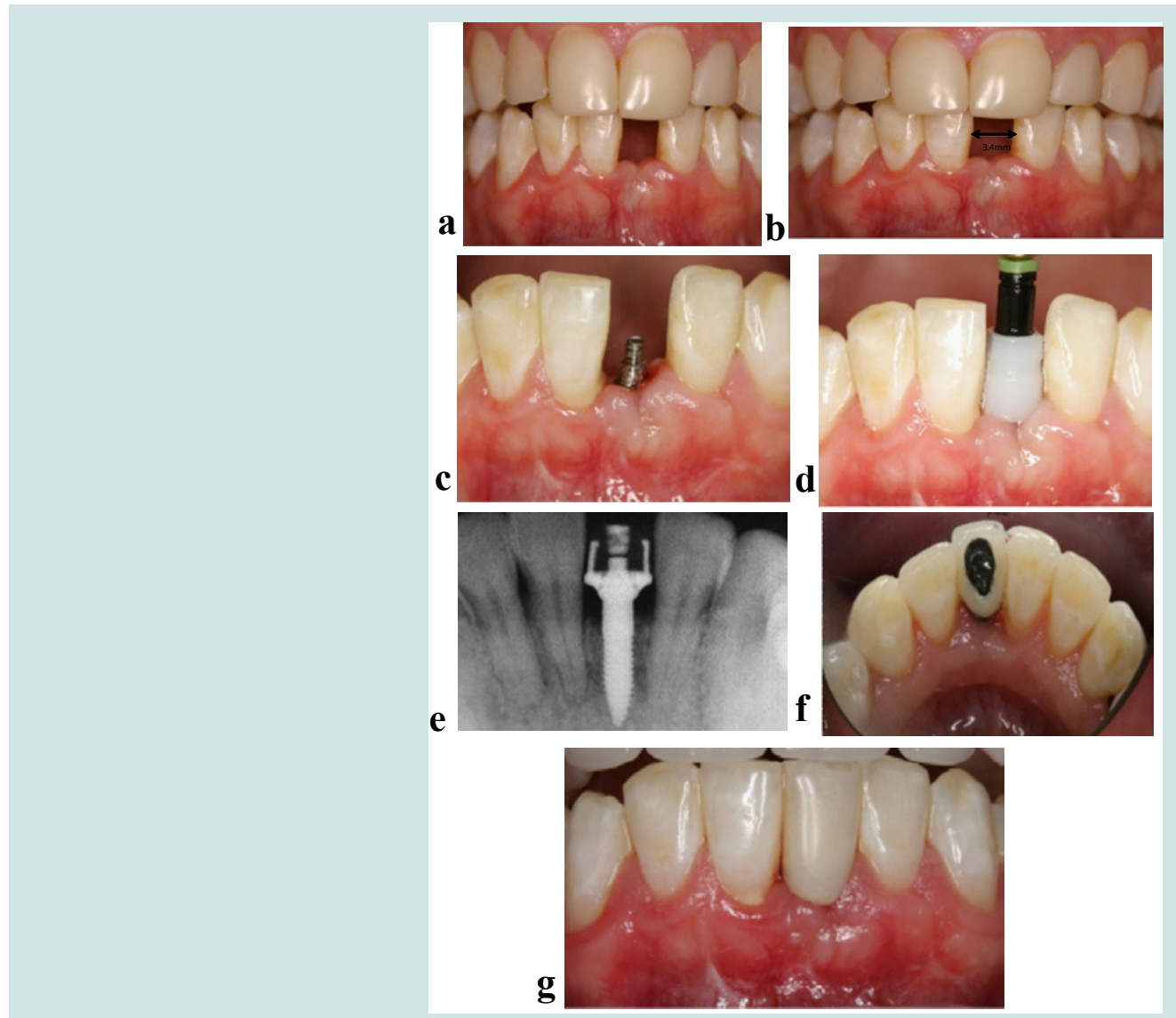

Figure 3: Case illustration of utilizing transitional implant. (a) Initial clinical presentation. (b) Buccal clinical picture shows interdental space of $3.4 \mathrm{~mm}$. (c) $2.2 \mathrm{~mm}$ transitional implant placed. (d) Impression copping. (e) Periapical Radiograph. (f) Occlusal aspect of final screw retained crown. (g) Facial aspect of final crown. 

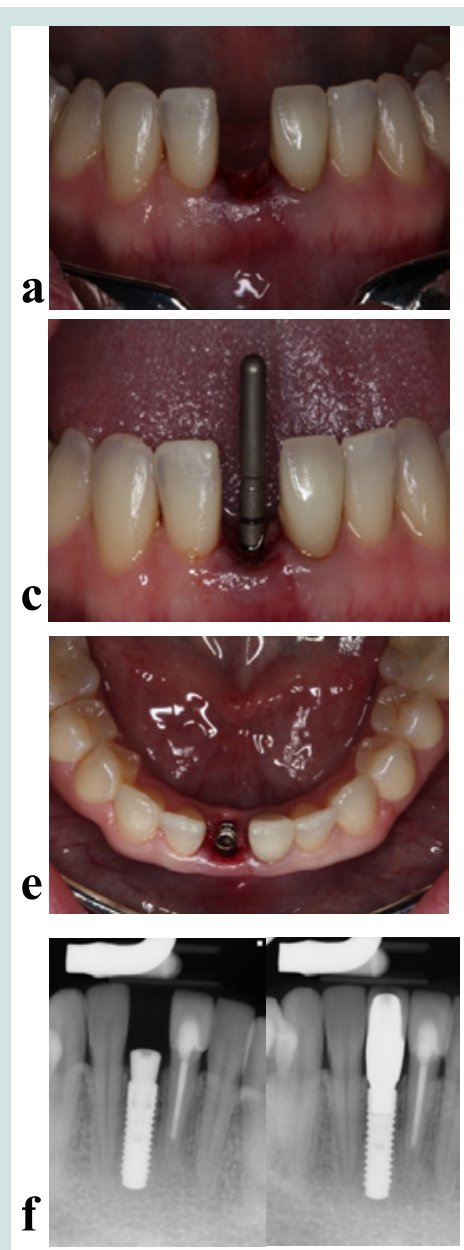

h

d
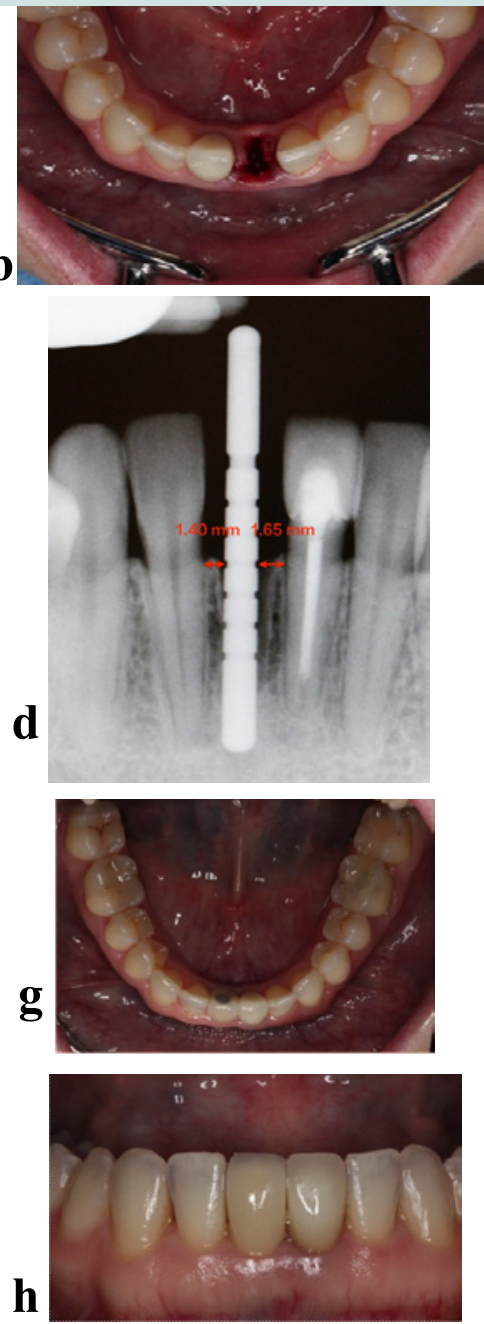

Figure 4: Case illustration of utilizing $3.3 \mathrm{~mm}$ diameter implant with the platform switching protocol. (a) Clinical buccal view after a traumatic tooth extraction (b) Occlusal aspect of extraction socket (c) Buccal view with depth gauge in place (d) Periapical radiograph shows limited mesio-distal distance. (e) Implant placed restoratively driven. (f) Periapical radiographs after implant healing and final delivery of Screw retained metal-ceramic crown. $(\mathrm{g}$ and $\mathbf{h}$ ) Clinical occlusal and facial view of final crown.

fracture. 2) Use of a transitional implant of 1.8-2.8 mm diameter. Klein in a systematic review of the literature categorizes narrow diameter implants into three categories, implant diameter $<3 \mathrm{~mm}$ (category 1 ), and implant diameter 3 to $3.25 \mathrm{~mm}$ (category 2) and implant diameter 3.3 to $3.5 \mathrm{~mm}$ (category 3). Narrow diameter implants used in option 2 in this study were all category 1 according to the Klein classification [16]. Transitional implants with a diameter of less than $3 \mathrm{~mm}$ were originally introduced as transitional implants that would allow patients undergoing implant therapy to avoid removable provisional dentures. These implants were ultimately intended to be removed due to the risk of fracture and non-osseointegration $[17,18]$. Surprisingly, these implants showed a bone-to-implant contact similar to that of implants with conventional diameters [19]. In 2007, Froum et al. reported $100 \%$ survival of 48 implants 1 to 5 years post-loading in 27 patients who received $1.8-2.8 \mathrm{~mm}$ diameter implants as permanent implants [20]. Others have shown similar high success rates. In 2008, the US Food and Drug Administration (FDA) approved the use of narrow diameter implants in the human jaws for long-term use [21].
However, there is limited information on the esthetic evaluation of small diameter implants used in anterior esthetic areas and these implants with less implant-to-bone surface area may result in increased rates of failure or fracture. 3) The last option is placing a 3.0$3.7 \mathrm{~mm}$ diameter implant to achieve an appropriate implant-to-bone surface area while utilizing a platform switching protocol, which is a widely used technique, to minimize resorption of the marginal bone and maintain the distance from implant to adjacent teeth. (Platform switching became more popular connection configuration and is incorporated in some implant designs by different manufacturers). Small diameter implants are often chosen for cases where there is a reduced availability of alveolar ridge width or interdental space. However, the reduced surface area for osseointegration $[22,23]$ and the increased risk for implant fracture [24,25] in such cases may contradict the use of small diameter implants. However, mechanical tests have shown higher tensile and fatigue strength of zirconium compared to pure titanium. Small width zirconium implants, together with the use of platform-switching, can reduce bone resorption when 


\begin{tabular}{|c|c|c|c|c|c|c|c|c|c|}
\hline Subject & Site & Gender & Age & $\begin{array}{c}\text { Period of } \\
\text { follow up } \\
\text { (months) }\end{array}$ & $\begin{array}{c}\text { Type of implant and } \\
\text { diameter }\end{array}$ & $\begin{array}{c}\text { Type of } \\
\text { treatment } \\
\text { option* }\end{array}$ & $\begin{array}{c}\text { Mesial papilala } \\
\text { index score } \\
\text { (PIS) }\end{array}$ & $\begin{array}{c}\text { Distal papilla } \\
\text { index score } \\
\text { (PIS) }\end{array}$ & $\begin{array}{c}\text { Facial gingival } \\
\text { recession } \\
\text { (mm) }\end{array}$ \\
\hline \hline 1 & $\# 24$ & $\mathrm{M}$ & 40 & 30 & MegaGen $4.0 \times 11 \mathrm{~mm}$ & 1 & 3 & 2 & 0.5 \\
\hline 2 & $\# 25$ & $\mathrm{M}$ & 65 & 18 & $3 i 3.75 \times 13 \mathrm{~mm}$ & 1 & 2 & 2 & 0.5 \\
\hline 3 & $\# 25$ & $\mathrm{M}$ & 45 & 60 & EBI $4.1 \times 11 \mathrm{~mm}$ & 1 & 2 & 3 & 1 \\
\hline 4 & $\# 24$ & $\mathrm{M}$ & 62 & 8 & EBI $4.1 \times 13 \mathrm{~mm}$ & 1 & 2 & 3 & 0 \\
\hline 5 & $\# 24$ & $\mathrm{M}$ & 25 & 36 & Dentatus $2.2 \mathrm{~mm}$ & 2 & 2 & 3 & 1 \\
\hline 6 & $\# 24$ & $\mathrm{M}$ & 33 & 11 & Dentatus $2.2 \mathrm{~mm}$ & 2 & 2 & 2 & 0.5 \\
\hline 7 & $\# 25$ & $\mathrm{~F}$ & 20 & 50 & Dentatus $2.2 \mathrm{~mm}$ & 2 & 3 & 2 & 0 \\
\hline 8 & $\# 24$ & $\mathrm{M}$ & 55 & 42 & Dentatus $2.2 \mathrm{~mm}$ & 2 & 2 & 3 & 0 \\
\hline 9 & $\# 25$ & $\mathrm{~F}$ & 38 & 4 & Straumann $3.3 \times 10 \mathrm{~mm}$ & 3 & 3 & 2 & 0.5 \\
\hline 10 & $\# 24$ & $\mathrm{M}$ & 57 & 4 & Straumann $3.3 \times 12 \mathrm{~mm}$ & 3 & 2 & 3 & 0.5 \\
\hline 11 & $\# 23$ & $\mathrm{~F}$ & 59 & 6 & Straumann $3.3 \times 12 \mathrm{~mm}$ & 3 & 3 & 3 & 0 \\
\hline 12 & $\# 24$ & $\mathrm{~F}$ & 33 & 12 & Straumann $3.3 \times 12 \mathrm{~mm}$ & 3 & 3 & 2 & 0 \\
\hline 13 & $\# 25$ & $\mathrm{M}$ & 54 & 24 & Straumann $3.3 \times 12 \mathrm{~mm}$ & 3 & 3 & 3 & 0 \\
\hline
\end{tabular}

Table 1: Summery of study sample and outcome of different treatment options

the implants are placed closer than $1.5 \mathrm{~mm}$ to the adjacent teeth without compromising implant strength [26]. As a clinician, it is necessary to understand the limitations and indications of each of the treatment options. The purpose of this case report is to review and report the result of the techniques that can be used in patients who have limited mesial-distal distance between implant and adjacent teeth $(<6 \mathrm{~mm})$.

\section{Platform switching}

The concept, which involves an abutment of decreased diameter relative to the implant, is sometimes referred to as platform switching $[27,28]$. While many consider platform switching to be a new concept, it has been incorporated into various systems for over 20 years [2931].

Platform switching moves the abutment-implant interface inward, away from the outer circumference of the implant (Figure $3)$. This has been reported to decrease crestal bone loss, preserve tissue height, and promote soft tissue health [32]. Vela-Nebot et al. also reported dramatically less bone loss when using implant systems incorporating a narrower diameter of restorative components relative to implant diameter [33]. A comprehensive literature review of 10 studies and 1239 implants by Atieh et al. showed strong evidence of less bone loss around the platform switched implants, although there was no difference in overall implant survival. The authors also noted that a more favorable bone response was seen when the platform switch was $0.4 \mathrm{~mm}$ or greater [34]. Wagenberg and Froum followed 94 platform switched connections over 11 years and found that approximately $75 \%$ showed no radiographic bone loss with $88 \%$ displaying $0.8 \mathrm{~mm}$ or less bone loss [35].

\section{Papillae development}

The possibility of papilla fill is greatly enhanced when interproximal bone is preserved, creating a reasonable opportunity to provide a desirable distance of $5 \mathrm{~mm}$ or less from the proximal contact to the interseptal bone as described in the literature for natural teeth as well as recently for implants immediately adjacent to natural teeth [36-39].

Degidi et al. examined 152 implants and 99 inter-implant sites and found that optimum inter-implant distance for papilla development was greater than $2 \mathrm{~mm}$ but less than $4 \mathrm{~mm}$. They also found that optimum bone to contact height should be 3 to $4 \mathrm{~mm}$ and that papilla height decreased dramatically when this distance exceeded $6 \mathrm{~mm}$ [40].

Tarnow et al. also concluded that less interproximal bone loss occurs as inter-implant distance increases, while recommending a minimum of $3 \mathrm{~mm}$, lending further support to their earlier mentioned recommendation of using standard to narrow diameter implants in the esthetic zone [41].

\section{Bone availability}

In aesthetic areas, the use of dental implants as replacements for lost permanent teeth remains an important challenge due to the difficulty of restoring the natural sulcus and papillary anatomical appearance around the implants. Inadequate facial bone is a common problem that can present itself at any time following extraction and often leads to a more lingual implant placement and an anterior ridge lap restoration [32]. In an attempt to avoid this situation, osseous grafting or regeneration techniques are used $[42,43]$.

\section{Distraction osteogenesis}

Distraction osteogenesis is a predictable way to gain vertical bone height, which involves gradual, controlled displacement of the surgically created bone fragments that result in concurrent expansion of soft tissue and bone volume [44].

Distraction osteogenesis is recommended for the treatment of a several clinical situations including severe atrophy of edentulous ridges, segmental deficiencies of alveolar ridge, narrow alveolar ridges, where horizontal distraction can be utilized, graduate vertical movement of ankylosed teeth when orthodontic displacement is impossible and for graduate vertical shift of an osseointegrated implants together with the surrounding alveolar bone [45].

Although alveolar distraction has proven to be successful for treating alveolar ridge deficiency, it has some intraoperative and postoperative complications. The most common complication was insufficient bone formation following the consolidation period (22 cases, $8 \%$ ), followed by regression of distraction distance (18 cases, $7 \%)$. Damage to vessels and nerves, or bone fracture, are potentially major limitations of this technique. The occurrence of paresthesia in 
Citation: Alodadi A, Kreingsak T, Hazlina B, Ghani A, Angie MML, et al. Various Treatment Options for the Single Implant in the Mandibular Anterior Region. J Oral Bio. 2016; 3(1): 7

the present review was 11-28\% [46]. During alveolar distraction, the distracted segment may incline lingually because of the lingual muscles [47]. Relapse of distraction in generated bone might occur during the late period of healing, which leads to a loss of approximately $1.5 \mathrm{~mm}$ or $20 \%$ of the distracted bone height [48]. In only bone grafting, the expected mean resorption during the first 4-6 months was reported to be between $25 \%$ and $44 \%$ [49]. Even when an implant can be placed, a thin plate of facial bone is often all that remains, leading to thread exposure or unpredictable future tissue height [50]. However, grafting cannot solve the mesio-distal space problem.

The purpose of this case report is to report three treatment options for patients with limited mesial-distal distance between implant and adjacent teeth $(<6 \mathrm{~mm})$.

- Cantilever crown from 3.75-4.75 mm diameter implant;

- Use of transitional implant of 1.8-2.8 mm diameter; or

- Placing a 3.0-3.7 $\mathrm{mm}$ diameter implant to achieve an appropriate implant-to-bone surface area.

\section{Material and Methods}

Clinical data in this study was obtained from the Implant Database (ID) in the Ashman Department of Periodontology and Implant Dentistry at New York University College of Dentistry. The ID was certified by the Office of Quality Assurance at NYUCD. This study is in compliance of the Health Insurance Portability and Accountability Act (HIPAA) requirements. Thirteen subjects requiring single implant placement in the lower anterior esthetic area were included in this case series from the anonymous database. One of these three options was used appropriately to correct the lower incisor loss for each patient, which are the following:

- Option 1: Cantilever crown (2 unit fixed restoration) over one standard implant,

- Option 2: Use of a transitional implant, or

- Option 3: Placement of a $3.3 \mathrm{~mm}$ diameter implant with the platform switching protocol (Figure 4).

The thirteen patients who had received implants in the anterior mandibular areas were evaluated to determine facial bone and marginal mucosal levels as well as papillary changes at 4 months to 5 years following insertion of the final restorations. The Papilla Index Score (PIS) was used to determine the status of the interproximal papillae (18). The index (0-4) determined papillae height as follows:

- 0 : No papilla is present

- 1 : Less than half the papilla is present

- 2 : At least half of the papilla is present, but not all the way up to the contact point between the teeth

- 3 : Papilla fills the entire interproximal space and is in good harmony with the adjacent papillae

- 4 : Papilla is hypertrophic and covers too much of the singleimplant restoration and/or the adjacent tooth.

Each patient had been recalled at 2- to 3-month intervals for maintenance and reassessment. Measurements were taken at 6-month intervals. Thirteen subjects requiring single implant placement in the lower anterior esthetic area were included in this case series from the anonymous database. Nine PFM crowns and four splinted cantiliver PFM crowns were restored in this case series.

\section{Inclusion criteria}

1. Patient requiring an implant placement in the lower anterior after loss of one lower incisor.

2. Patient must be at least 17-years old and completed his/her facial growth.

\section{Exclusion criteria}

1. Smoker, who smokes more than 10 cigarettes per day.

2. Untreated periodontitis.

3. Active caries.

4. Severe bruxism and/orclenching.

The surgical and restorative procedures of each implant manufacturer were followed.

\section{Results}

In this case series, thirteen patients received thirteen implants, which were loaded for periods of 4 months to 5 years post insertion. No implant or prosthesis had to be removed or replaced during the follow-up period. There was one patient who had a 3.75-4.75 mm diameter implant with cantilever that had a screw loosening, due to excessive non-axial occlusal forces on the cantileverpontic. For the other, neither a surgical nor a prosthetic complication was seen. Considering the follow-up time, there was no obvious mesial or distal bone loss shown in the radiographs. The average mesial PIS was 2.46 and the average distal PIS was 2.54. The average facial mucosal change was $0.45 \mathrm{~mm}$ (Table 1 ).

\section{Discussion}

This study demonstrates and presents results of three different treatment options to replace missing mandibular tooth. Transitional implant behaves positively in maintaining inter-proximal bone beak and related soft tissues. Besides, it allows placement in limited mesial-distal arch spaces. Soft and hard tissue heals around one-piece implant different than that around two pieces implant. Hermann et al. demonstrate in an animal study that the first bone implant contact determined by the location of the rough-smooth border. However, biological width and the amount of bone resorption were determined by the interface between the two-piece implant [51].

In the last option (use of 3.0-3.7 mm diameter implants with platform switched) the results of this study showed that a platformswitched implant can be placed 1-mm from an adjacent tooth and still maintain the bone peak. These results are in agreement with a previous published study that suggested that a $2 \mathrm{~mm}$ distance between adjacent platform switched implants was able to maintain the interimplant bone peak. This characteristic allows for an ideal position and emergence profile while maintaining the bone peak between the 
Citation: Alodadi A, Kreingsak T, Hazlina B, Ghani A, Angie MML, et al. Various Treatment Options for the Single Implant in the Mandibular Anterior Region. J Oral Bio. 2016; 3(1): 7

implant and tooth with better support for the soft tissues esthetic and functional results. This is especially important when there is a reduced mesiodistal distance, such as in the mandibular incisors.

Aglietta et al. reported the survival rates of short-span implantsupported cantilever fixed partial prostheses. They reported five-year estimates for peri-implantitis were 5.4\% (95\% CI, 2.0-14.2\%) and 9.4\% (95\% CI, 3.3-25.4\%) at implant and prosthesis levels, respectively. Veneer fracture (5-year estimate; 10.3\%; 95\% CI, 3.9-26.6\%) and screw loosening (5-year estimate, $8.2 \%$; 95\% CI, 3.9-17.0\%) represented the most common complications, followed by loss of retention (5-year estimate, 5.7\%; 95\% CI, 1.9-16.5\%) and abutment/ screw fracture (5year estimate, $2.1 \%$; $95 \% \mathrm{CI}, 0.9-5.1 \%$ ) [52].

Staffford suggested that solely implant-supported FPP or implant-supported single crowns should be the first treatment option. Tooth-implant-supported FPP, tooth-supported FPP with cantilever extensions, and resin bonded fixed restorations are to be considered secondary treatment options because of their higher estimated failure rates [53].

\section{Conclusion}

The results from this case series show that the use of platform switched implants can minimize loss of the marginal bone in cases that one cannot maintain $1.5 \mathrm{~mm}$ between natural adjacent teeth and implant. Narrow diameter implants $(3.0-3.7 \mathrm{~mm})$ and cantilever crowns on regular diameter implants $(3.75-4.7 \mathrm{~mm})$, can provide more than $1.5 \mathrm{~mm}$ space from implant to adjacent teeth to preserve the marginal bone in that area. These 3 treatment options can be used to maintain the appropriate bone level in patients that have limited distance between implant and adjacent teeth. Although the results of these 3 options in this case report shows the appropriate bone level around the implants and can preserve the bone adjacent to the teeth, each option has its own advantages and disadvantages that one must consider. Larger sample sizes and long term follow-up studies are needed to evaluate the long-term success of these treatment options.

\section{References}

1. Fleigl JD 3rd, Salmon CA, Piper JM 2nd (2011) Treatment options for the replacement of missing mandibular incisors. J Prosthodont 20: 414-420.

2. Bain CA (2004) Treatment planning in general dental practice: case presentation and communicating with the patient. Dent Update 31: 72-76,7880,82

3. Adell R, Lekholm U, Rockler B, Brånemark PI (1981) A 15-year study of osseointegrated implants in the treatment of the edentulous jaw. Int $\mathrm{J}$ Ora Surg 10: 387-416.

4. Adell R, Eriksson B, Lekholm U, Brånemark PI, Jemt T (1990) Long-term follow-up study of osseointegrated implants in the treatment of totally edentulous jaws. Int J Oral Maxillofac Implants 5: 347-359.

5. Jemt T, Lekholm U (1993) Oral implant treatment in posterior partially edentulous jaws: a 5-year follow-up report. Int J Oral Maxillofac Implants 8 : 635-640.

6. Buser D, Mericske-Stern R, Bernard JP, Behneke A, Behneke N, et al. (1997) Long-term evaluation of non-submerged ITI implants. Part 1: 8-year life table analysis of a prospective multi-center study with 2359 implants. Clin Oral Implants Res 8: 161-172

7. Buser D, Mericske-Stern R, Dula K, Lang NP (1999) Clinical experience with one-stage, non-submerged dental implants. Adv Dent Res 13: 153-161.

8. Simion M, Dahlin C, Trisi P, Piattelli A (1994) Qualitative and quantitative comparative study on different filling materials used in bone tissue regeneration: a controlled clinical study. Int J Periodontics Restorative Dent14: 198-215.

9. Simion M, Scarano A, Gionso L, Piattelli A (1996) Guided bone regeneration using resorbable and nonresorbable membranes: a comparative histologic study in humans. Int J Oral Maxillofac Implants 11: 735-742.

10. Pikos MA (1999) Block autografts for localized ridge augmentation: Part I. The posterior maxilla. Implant Dent 8: 279-285

11. Degidi M, Piattelli A, Carinci $F$ (2008) Clinical outcome of narrow diamete implants: a retrospective study of 510 implants. J Periodontol 79: 49-54.

12. Hallman M (2001) A prospective study of treatment of severely resorbed maxillae with narrow nonsubmerged implants: results after 1 year of loading. Int J Oral Maxillofac Implants 16: 731-736.

13. Zinsli B, Sagesser T, Mericske E, Mericske-Stern R (2004) Clinical evaluation of small-diameter ITI implants: a prospective study. Int $\mathrm{J}$ Oral Maxillofac Implants 19: 92-99.

14. Nevins M, Mellonig JT, Clem DS 3rd, Reiser GM, Buser DA (1998) Implants in regenerated bone: long-term survival. Int J Periodontics Restorative Dent 18: $34-45$.

15. Fugazzotto PA (2005) Success and failure rates of osseointegrated implants in function in regenerated bone for 72 to 133 months. Int J Oral Maxillofac Implants 20: 77-83.

16. Klein MO, Schiegnitz E, Al-Nawas B (2014) Systematic review on success of narrow-diameter dental implants. Int J Oral Maxillofac Implants 29: 43-54.

17. Froum S, Emtiaz S, Bloom MJ, Scolnick J, Tarnow DP (1998) The use of transitional implants for immediate fixed temporary prostheses in cases of implant restorations. Pract Periodontics Aesthet Dent 10: 737-746

18. Petrungaro PS (1997) Fixed temporization and bone-augmented ridge stabilization with transitional implants. Pract Periodontics Aesthet Dent 9: 1071-1078.

19. Froum SJ, Simon H, Cho SC, Elian N, Rohrer MD, et al. (2005) Histologic evaluation of bone-implant contact of immediately loaded transitional implants after 6 to 27 months. Int J Oral Maxillofac Implants 20: 54-60.

20. Froum SJ, Cho SC, Cho YS, Elian N, Tarnow D (2007) Narrow-diameter implants: a restorative option for limited interdental space. Int J Periodontics Restorative Dent 27: 449-455.

21. Food and Drug Administration (2008) 510(k) Summary K072917. US Dept of Health and Human Services, Rockville, MD.

22. Ivanhoff CJ, Sennerby L, Johansson C, Rangert B, Lekholm U (1997) Influence of implant diameters on the integration of screw implants. An experimental study in rabbits. Int J Oral and Maxillofac Surg 26: 141-148.

23. Winkler S, Morris HF, Ochi S (2000) Implant survival to 36 months as related to length and diameter. Ann of Periodontol 5: 22-31.

24. Quek CE, Tan KB, Nicholls JI (2006) Load fatigue performance on a singletooth implant abutment system: effect of diameter. Int J Oral Maxillofac Implants 21: 929-936

25. Allum SR, Tomlinson RA, Joshi R (2008) The impact of loads on standard diameter, small diameter and mini implants: a comparative laboratory study. Clinical Oral Implants Res 19: 553-559.

26. Vela X, Méndez V, Rodríguez X, Segalá M, Tarnow DP (2012) Crestal bone changes on platform- switched implants and adjacent teeth when the toothimplant distance is less than $1.5 \mathrm{~mm}$. Int J Periodontics Restorative Dent 32 149-155.

27. Lazzara RJ, Porter SS (2006) Platform switching: a new concept in implant dentistry for controlling post restorative crestal bone levels. Int J Periodontics Restorative Dent 26: 9-17

28. Prosper L, Redaelli S, Pasi M, Zarone F, Radaelli G, et al. (2009) A randomized prospective multicenter trial evaluating the platform-switching technique for the prevention of post restorative crestal bone loss. Int $\mathrm{J}$ Oral Maxillofac Implants 24: 299-308. 
Citation: Alodadi A, Kreingsak T, Hazlina B, Ghani A, Angie MML, et al. Various Treatment Options for the Single Implant in the Mandibular Anterior Region. J Oral Bio. 2016; 3(1): 7.

ISSN: $2377-987 X$

29. Morris HF, Ocho S, Orenstein IH, Petrazzuolo V (2004) AICRG, Part V: Factors influencing implant stability at placement and their influence on survival of Ankylos implants. J Oral Implantol 30: 162-170.

30. Norton MR (2000) In vitro evaluation of the strength of the conical implant to abutment joint in two commercially available implant systems. J Prosthet Dent 83: 567-571.

31. Mangano C, Mangano F, Piatelli A, lezzi G, Mangano A, et al. (2010) Prospective clinical evaluation of 307 single-tooth morse taper-connection implants: a multicenter study. Int J Oral Maxillofac Implants 25: 394-400

32.Leblebicioglu B, Rawal S, Mariotti A (2007) A review of the functional and esthetic requirements for dental implants. J Am Dent Assoc 138: 321-329.

33. Vela-Nebot $X$, Rodriguez-Ciurana $X$, Rodado-Alonso C, Segalá-Torres M (2006) Benefits of an implant platform modification technique to reduce crestal bone resorbtion. Implant Dent 15: 313-320.

34. Atieh MA, Ibrahim HM, Atieh AH (2010) Platform switching for marginal bone preservation around dental implants: a systematic review and meta-analysis. J Periodontol 81: 1350-1366.

35. Wagenberg B, Forum SJ (2010) Prospective study of 94 platform-switched implants observed from 1992 to 2006. Int J Periodontics Restorative Dent 30 : 9-17.

36. Tarnow DP, Magner AW, Fletcher P (1992) The effect of the distance from the contact point to the crest of bone on the presence or absence of the interproximal dental papilla. J Periodontol 63: 995-996.

37. Choquet V, Hermans M, Adriaenssens P, Daelemans P, Tarnow DP, et al (2001) Clinical and radiographic evaluation of the papilla level adjacent to single tooth dental implants. A retrospective study in the maxillary anterior region. J Periodontol 72: 1364-1371

38. Gastaldo JF, Curry PR, Sendyk WR (2004) Effect of the vertical and horizontal distances between adjacent implants and between a tooth and an implant on the incidence of interproximal papilla. J Periodontol 75: 1242-1246.

39. Lops D, Chiapasco M, Rossi A, Bressan E, Romeo E (2008) Incidence of inter-proximal papilla between a tooth and an adjacent immediate implant placed into a fresh extraction socket: 1-year prospective study. Clin Ora Implants Res 19: 1135-1140.

40. Degidi M, Novaes AB Jr, Nardi D, Piattelli A (2008) Outcome analysis of immediately placed, immediately restored implants in the esthetic area: the clinical relevance of different interimplant distances. J Periodontol 79: 1056 1061.
41. Tarnow DP, Cho SC, Wallace SS (2000) The effect of inter-implant distance on the height of inter-implant bone crest. J Periodontol 71: 546-549.

42. Fagan MC, Owens H, Smaha J, Kao RT (2008) Simultaneous hard and soft tissue augmentation for implants in the esthetic zone: report of 37 consecutive cases. J Periodontol 79: 1782-1788

43. Buser D, Chen ST, Weber HP, Belsar UC (2008) Early implant placement following single tooth extraction in the esthetic zone: biologic rationale and surgical procedures. Int J Periodontics Restorative Dent 28: 441-451.

44. Hashemi HM, Javidi B (2010) Comparison between interpositional bone grafting and osteogenic alveolar distraction in alveolar bone reconstruction. J Oral Maxillofac Surg 68: 1853-1858.

45. Urbani G, Consolo U, Lombardo G (2001) Alveolar bone distraction for implant placement. In: Samchukov ML, Cope JB, Cherkasin AM, (Eds). Craniofacial distraction osteogenesis. St Louis: Mosby, pp. 423-432.

46. Saulacic N, Zix J, lizuka T (2009) Complication rates and associated factors in alveolar distraction osteogenesis: a comprehensive review. Int $\mathrm{J}$ Oral Maxillofac Surg 38: 210-217.

47. Uckan S, Haydar SG, Dolanmaz D (2002) Alveoar distraction: analysis of 10 cases. Oral Surg Oral Med Oral Pathol Oral Radiol Endod 94: 561-565.

48. Hwang SJ, Jung JG, Jung JU, Kyung SH (2004) Vertical alveolar bone distraction at molar region using lag screw principle. J Oral Maxillofac Surg 62: $787-794$

49. Cordaro L, Amade DS, Cordaro M (2002) Clinical results of alveolar ridge augmentation with mandibular block bone grafts in partially edentulous patients prior to implant placement. Clin Oral Implants Res 103-111.

50. Rodriguez AM, Rosenstiel SF (2012) Esthetic considerations related to bone and soft tissue maintenance and development around dental implants: report of the Committee on Research in Fixed Prosthodontics of the American Academy of Fixed Prosthodontics. J Prosthet Dent 108: 259-267.

51. Hermann JS, Buser D, Schenk RK, Cochran DL (2000) Crestal bone changes around titanium implants. a histometric evaluation of unloaded nonsubmerged and submerged implants in the canine mandible. J Periodontol 71: $1412-1424$

52. Aglietta M, Siciliano VI, Zwahlen M, Brägger U, Pjetursson BE, et al. (2009) A systematic review of the survival and complication rates of implant supported fixed dental prostheses with cantilever extensions after an observation period of at least 5 years. Clin Oral Implants Res 20: 441-451.

53. Stafford GL (2010) Survival rates of short-span implant-supported cantilever fixed dental prostheses. Evid Based Dent 11: 50-51. 